\title{
The Role of Rational Emotive Behavioral Therapy on Students
}

\section{Adjustment}

\author{
Farideh Hamidi, ${ }^{1}$ Farshid Paidar, ${ }^{2,}$ and Farangis Mohammadi ${ }^{2}$ \\ ${ }^{1}$ Associate Professor of Psychology, Department of Educational Sciences, Shahid Rajaee Teacher Training University, Tehran, IR Iran \\ ${ }^{2}$ Master of School Counseling, Department of Educational Sciences, Shahid Rajaee Teacher Training University, Tehran, IR Iran \\ "Corresponding author: Farshid Paidar, Master of School Counseling, Department of Educational Sciences, Shahid Rajaee Teacher Training University. Tehran, IR Iran. Tel: \\ +98-9387289440, E-mail: Farshid_paydar@yahoo.com
}

Received 2016 June 14; Revised 2016 July 02; Accepted 2016 August 14.

\begin{abstract}
Background: Adjustment is one of the factors that promote mental health and academic achievement of students.

Objectives: This study examined the role of rational emotive behavior therapy on adjustment among high school male students of Bostan-Abad city.

Methods: The method was experimental and the statistical population included all 2nd and 3rd grade high school students of the city of Bostan-Abad enrolled in the academic year 2014 to 2015, that were estimated as 680 students. To select the sample, the adjustment inventory for school students (AISS Singh Sinha, 1993) was completed by 150 students, of whom 30 students met the required conditions, and were divided randomly to two groups ( 15 in the experimental and 15 in the control group). Rational emotive behavior therapy was conducted during eight sessions.

Results: After entering the data into the SPSS20 software, the data were analyzed using analysis of covariance (ANCOVA), which showed that after the intervention, the relationship among general adjustment and its components in the control and experiment group was significant $(\mathrm{P}<0.01)$. In this regard, Rational Emotive Behavior therapy enhances the overall adjustment $\left(\mathrm{F}_{(1,27)}=15.02, \mathrm{P}\right.$ $\left.=0.001, \eta_{\mathrm{P}}{ }^{2}=0.46\right)$ among the students.

Conclusions: The results indicate that rational emotive behavior therapy improves the overall adjustment and its components in high school male students.
\end{abstract}

Keywords: Rational Emotive Behavior Therapy, Adjustment, Students

\section{Background}

Adolescence is not only a simple transition from childhood to physical and physiological maturity, but more importantly, this period is involved with the formation of the mind structure, soul and growth of perfection (1). The speed and scale of changes in adolescence is so high that not only teens but also the parents and caregivers are also confused and involved (2). Therefore, adolescents at this age may have many problems in adapting to school and their peers. Also, one of the objectives for educating students is to achieve adjustment and effective relationships with others as well as social acceptance.

Adjustment as the most important sign of mental health, has received the attention of many sociologists, psychologists and special educators in the recent decades and the criteria for measuring the growth of each person, is their level of adjustment with others. Others include people such as friends, family members, relatives, neighbors and so on. Social development is not only effective in coping with people, but also impacts career success and social progress (3). Adjustment corresponds to the notion of accommodation in the Piaget's theory. In accommoda- tion, the cognition of the person changes due to inputs and this change creates a kind of adjustment between schemas and the truth about the person (4). Adjustment refers to the establishment of a satisfactory relationship between oneself and the environment and includes individual responses that lead to effective adjustment and coordination with his/her surrounding environment. Hence, achieving a desired level of adjustment in different fields facilitates acquisition of needs and desires and fulfillment of individual aspirations (5).

Sinha and Singh (6) describe adjustment in three academic, social and emotional areas. The concept of academic adjustment refers to more than simply a student's academic potential. In other words, the motivation to learn, work to meet educational needs, having a clear sense of purpose and deliberate satisfaction with academic environment are involved in academic adjustment (7). Emotional adjustment is related to the mechanisms by which a person finds emotional stability (6). Social adjustment refers to interaction and adaptation of the individual with people and social structures, lack of concern related to exposure to people, and lack of the feeling of isolation (8). 
Increased adjustment has a significant influence on teenagers' mental health components, academic achievement, and their approach towards crisis situations $(5,9)$. Also it has been emphasized that due to the importance of adjustment and self-efficacy in adolescents' academic and social life, it is necessary to reinforce the adjustment variable among them through acceptable modalities (10).

The rational emotional behavior theory by Ellis is a valid theory in psychology. Philosophically, Ellis ideas borrow from some philosophers especially Zeno, Cicero and Epictetus. Epictetus, who lived in the fourth century BC, believed that humans do not become upset by things, but the attitude of people makes them upset and distracted (11). The basic premise of rational emotional behavior therapists is that emotion and behavior are mediated through cognitive processes (12).

According to Ellis, attitudes of people towards things direct their personal and social life and reflect their character. The attitude of a person consists of factors such as: thinking, emotions, passions and feelings that shape current and future behaviors of the individual. How a person reacts to an emotional, painful, joyful situation or decides, depends on his/her attitude towards these situations; in other words the relationship between thinking, emotion and behavior is a strong and indubitable relationship (13). Irrational thoughts that cause maladaptive behaviors are beliefs that dominate the mind of people and are a determining factor in how they interpret events (14). Lack of familiarity of students with correct ways of thinking could lead to exhaustion, anger, aggression, depression and delinquent behavior and their maladjustment. As seen in UK teenagers, smoking is the first solution they find for establishing their identity and gaining control over their lives (15). Cognitive behavior therapists believe that irrational beliefs are associated with maladaptive behaviors, so gaining insight into unrealistic beliefs will change the perceptions and interpretations that can modify maladaptive behaviors.

Because of the importance of the effects that a rational emotional behavior approach has on the belief systems of many people, many researchers have investigated its role and function to help different classes and groups of the society. Such studies include those investigating the effect of rational emotive behavior therapy in reducing anxiety in female high school students (16); the effect of treatment of rational emotive behavior therapy in stress coping strategies and self-efficacy (17); the effects of integrating rational emotive behavior therapy and art therapy in improving confidence and flexibility (18); and the effects of emotional education model on irrational beliefs and stress the of students (7).

Adjustment is a very important factor in student achievement. Researchers believe that high environmental pressures and training demands may be involved in emotional and behavioral problems and decrease students' competencies (19). In this regard, the researchers found that academic achievement is significantly predicted by social, emotional and academic adjustment. They also found that male students compared to female students are better able to adapt (20).

Regarding the above points, to evaluate the effectiveness of Rational Emotive Behavior Therapy on students seems necessary. Also, considering the importance of adjustment in the treatment and prevention of delinquency and mental disorders in adolescents as well as the emphasis of Ellis's Rational Emotive Behavior Therapy on dysfunctional attitudes and beliefs in this study, we attempted to answer the question of whether Rational Emotive Behavior group counseling of Elliss impacts students' adjustment.

\section{Objectives}

This study examined the role of rational emotive behavior therapy on adjustment of high school male students of Bostan-Abad city.

\section{Methods}

The present study was an experimental study with pretest-posttest design and a control group. In the present study, with purposive design, subjects were randomly selected and divided to experimental and control groups. Both groups received the pre-test, then the independent variable was applied for the experimental group and all subjects were examined for a final evaluation.

The target population included all second and third grade high school students living in Bostan-Abad city enrolled in the academic year of 2014 to 2015. The number of boy's high schools of this city was four and the total number of second and third grade students was 680 . The size of the sample of this study due to its experimental design was 30 students (21). The cluster sampling method was used. First, among the four high schools, one was selected and 150 questionnaires were distributed among second and third grade students. Among the respondents, 45 students obtained one standard deviation higher than the average in the adjustment scales. A total of 30 participants were randomly selected and assigned to two experimental and control groups ( $\mathrm{n}=15$ experimental, 15 control) randomly. 


\subsection{Instruments}

Adjustment Inventory of School Students (AISS) was developed by Sinha and Singh in 1997 to separate high school students (age group of 14 to 18 years) with good adjustment from students with poor adjustment in three adjustment areas (emotional, social, and educational) (6). The questionnaire was translated to Farsi by Karami in 2003 and its validity and reliability were measured (22). The total score of the three subscales provides the overall adjustment score. Each item of the questionnaire is considered a sign of maladjustment. The initial questionnaire contained 100 questions that were reduced to 60 questions after diverse considerations. The 60-item questionnaire on the final form was administered on 1950 students (1200 males and 750 females) of first, second and third grades at 40 high schools, who were selected randomly. The normal distribution of scores was tested using the chi-square formula and distribution was not significantly different with normal distribution (6).

The reliability and validity of the test: Sinha and Singh (6) estimated the validity coefficient of AISS by split-half method for total adjustment as 0.95 , and for the emotional, social and educational scales as 0.94, 0.93 and 0.96, respectively. Using the retest method, the total adjustment was obtained as 0.93 , and for the emotional, social and educational scales as 0.96, 0.90 and 0.93, respectively. Using Kuder-Richardson method, the total adjustment was obtained as 0.94 , and for the emotional, social and educational scales as 0.92, 0.92, 0.96, respectively (22). Fouladchang in his study reported the retest and KuderRichardson reliability coefficients for the questionnaire as 0.89 and 0.82 , respectively (23).

\subsection{Administration}

The content of therapy sessions was as follows. In the first session, members of the group were introduced, good relationships were established, the objectives were set, and the way to distinguish between proper and improper negative feelings was explained to teenagers. In the second session, group counseling was conducted with participation of members in order to learn the basic rules of the scientific method of thinking about ourselves, others, and life. In the third session, Ellis A-B-C model was taught. In the fourth session, the focus was on how to distinguish between wishes and musts, identifying the three main musts of Ellis and challenging them. In the fifth session, the focus was on how we can solve our real problems along with our emotional problems. Also, changing thoughts with practical actions was discussed. During the sixth session, four couple of beliefs were taught: 1) demandingness versus preferences, 2) awfulizing versus anti-awfulizing, 3) low frustration tolerance versus high frustration tolerance 4) self or other downing versus self/other acceptance. In the seventh session, adjustment and its components were described and how we can resolve adjustment issues was discussed from the perspective of Ellis. During the eighth session, how we can develop the power of not upsetting ourselves was explained to the members. Finally, a summary of all sessions was provided.

Treatment sessions were held once a week for the experimental group and during this period the control group did not receive any new therapy.

\subsection{Data Analysis Method}

To examine research dependent variables, descriptive statistics such as mean and standard deviation, and for testing the research hypotheses inferential statistics including Covariance analysis and Levin's variance homogeneity test were run. The level of significance was considered as 0.05 .

\section{Results}

All the participants of the study (100 percent) were boys. Furthermore, $26.7 \%, 53.3 \%$ and $20 \%$ of the participants were 16,17 , and 18 years old, respectively in the control group. In experimental group, 33.3\%, 53.3\% and 13.3\% were 16,17 and 18 years old, respectively. In the control group $46.7 \%$ of the participants were in the second grade and $53.3 \%$ were in the third. In the experimental group, $40.0 \%$ of the participants were in the second grade and $60.0 \%$ were in the third grade

This section presents the mean and standard deviation of high school students adjustment scores in the pre-test and post-test steps.

As Table 1 shows, the adjustment variable and its components were not very different regarding average scores on the posttest of the control group and the pre-test scores, but the adjustment scores among adolescents of the experimental group showed a significant difference in the posttest and pre-test scores. In fact, it can be seen in the experimental group that scores of high school students adjustment test and its sub-components declined compared to the pre-test.

To test for equality of variances, data were analyzed by Levin's test of homogeneity of variances. The results showed that the variances of the two groups of experimental and control was equal in overall adjustment score $(\mathrm{F}=$ $0.217, \mathrm{P}=0.645)$ as well as its components, including emotional adjustment $(\mathrm{F}=0.142, \mathrm{P}=0.709)$ social adjustment $(\mathrm{F}=0.064, \mathrm{P}=0.802)$ educational adjustment $(\mathrm{F}=0.147, \mathrm{P}$ $=0.705)$. The significance tests of multivariate analysis of 
Table 1. The Frequency Distribution of Demographic Variables

\begin{tabular}{|c|c|c|c|c|}
\hline \multirow[t]{2}{*}{ Variable } & \multicolumn{2}{|c|}{ Control Group } & \multicolumn{2}{|c|}{ Experimental Group } \\
\hline & Frequency & Percentage & Frequency & Percent \\
\hline \multicolumn{5}{|l|}{ Gender } \\
\hline Male & 15 & 100 & 15 & 100 \\
\hline \multicolumn{5}{|l|}{ Age } \\
\hline 16 & 4 & 26.7 & 5 & 33.3 \\
\hline 17 & 8 & 53.3 & 8 & 53.3 \\
\hline 18 & 3 & 20.0 & 2 & 13.3 \\
\hline \multicolumn{5}{|l|}{ Level of education } \\
\hline 2nd grade high school & 7 & 46.7 & 6 & 40.0 \\
\hline 3rd grade high school & 8 & 53.3 & 9 & 60.0 \\
\hline
\end{tabular}

Table 2. Descriptive Statistics of Adjustment and its Components

\begin{tabular}{|c|c|c|c|c|c|}
\hline \multirow[t]{2}{*}{ Variable } & \multirow[t]{2}{*}{ Evaluation stage } & \multicolumn{2}{|c|}{ Control } & \multicolumn{2}{|c|}{ Experimental } \\
\hline & & Mean & SD & Mean & SD \\
\hline \multirow{2}{*}{ Overall adjustment } & Pretest & 33.04 & 7.09 & 34.33 & 7.13 \\
\hline & Posttest & 31.93 & 6.54 & 19.06 & 7.21 \\
\hline \multirow{2}{*}{ Emotional adjustment } & Pretest & 11.67 & 2.41 & 11.53 & 2.16 \\
\hline & Posttest & 11.33 & 2.61 & 7.93 & 2.47 \\
\hline \multirow{2}{*}{ Social adjustment } & Pretest & 10.27 & 2.86 & 10.73 & 2.05 \\
\hline & Posttest & 10.07 & 2.31 & 5.40 & 2.09 \\
\hline \multirow{2}{*}{ Educational adjustment } & Pretest & 11.20 & 3.09 & 12.07 & 3.12 \\
\hline & Posttest & 10.53 & 2.72 & 6.27 & 3.36 \\
\hline
\end{tabular}

covariance including Pillai's effect, Wilk's Lambda, Hilting effect, etc. were conducted, and the value of Wilk's Lambda test and F were calculated as 0.319 and 18.520, with 26 degree of freedom 3, respectively. Thus, the null hypothesis can be rejected. In other words, the mean score of the participants in adjustment variables were significantly different between the control and experimental groups.

The result of ANCOVA on overall adjustment scores and its components after pretest control is shown in Table 3.

To further examine the scores of adjustment and its components in the control and experimental groups (with pre-test control) ANCOVA analysis was used. As Table 3 shows, calculated $\mathrm{F}$ for variables mean scores in the two experimental and control groups (with control pre-test) was significant at the $1 \%$ level of error; so the null hypothesis was rejected and it can be concluded with $99 \%$ confidence that the rational emotional behavior group therapy is effective on improving the overall adjustment $\left(\mathrm{F}_{(1,27)}=15.02\right.$, $\left.\mathrm{P}=0.001, \eta_{\mathrm{P}}{ }^{2}=0.46\right)$ and its components, including emotional adjustment $\left(\mathrm{F}_{(1,27)}=17.21, \mathrm{P}=<0.001, \eta_{\mathrm{P}}{ }^{2}=0.38\right)$, social adjustment $\left(\mathrm{F}_{(1,27)}=46.70, \mathrm{P}=<0.001, \eta_{\mathrm{P}}^{2}=0.63\right)$ and educational adjustment $\left(\mathrm{F}_{(1,27)}=16.65, \mathrm{P}=<0.001, \eta_{\mathrm{P}}{ }^{2}=\right.$ 0.38 ) among students.

\section{Discussion}

This study aimed to evaluate the effectiveness of rational emotional behavior group therapy on adjustment of students. The results showed that rational emotive behavior group therapy increases the overall adjustment and its three components in the experimental group compared with the control group in the posttest. In the recent years the relationship between adjustment and different variables was studied (e.g. hidden curriculum (24), selfregulation (25), academic performance (26), mentally retarded children and children with normal growth (27), and with vision loss (28)). The results of this test were consistent with the results of studies that examined therapy or group training with different approaches in order to influence adjustment through the intervention (29-31) and the answer given to the hypothesis was confirmed by other studies. To explain these findings, it should be noted that the rational emotional behavior group therapy helps students use their learning when dealing with problems of personal and social life and even education, in accordance with the philosophy that they have been taught, whether at school or outside of school, and have dominion over the thoughts, feelings and behavior.

Emotional rational behavior method helps people to express their strong feelings when disrupted and upset. 
Table 3. Result of One-Way Covariance on Overall Adjustment Scores and its Components

\begin{tabular}{|c|c|c|c|c|c|c|}
\hline Source of Changes & SS & Df & MS & $\mathbf{F}$ & $\mathbf{P}$ & Eta2 \\
\hline Overall adjustment & 211.794 & 1 & 211.794 & 15.024 & 0.001 & 0.468 \\
\hline Emotional adjustment & 95.631 & 1 & 95.631 & 17.216 & $<0.001$ & 0.389 \\
\hline Educational adjustment & 149.226 & 1 & 149.226 & 16.659 & $<0.001$ & 0.382 \\
\hline
\end{tabular}

However, this method distinguishes between useful and appropriate sense of fear, shame or hurt and the bad and destructive sense of panic, depression, anger and selfreprimand. This method teaches people the way of coping with life problems and feeling better when faced with difficulties. It teaches not only the way of controlling fate and not getting upset, but also teaches them how to use their powers of self-government. This method helps people make a profound change in their philosophy and reach an entirely new perspective on life, to set aside Polanyi's positive thinking that is a temporarily coping strategy and is usually disadvantageous in the long term. This method helps people accept responsibility for upsetting themselves and seek to reduce it and stop blaming parents or social conditions. This method helps people be independent and autonomous; and instead of credulity and obedience to what others think, they should think independently. This method teaches people how they can have whims, desires, tastes and goals while keeping their current values. It also teaches them that their expectations should not be noble and God-like; i.e. should and musts and absolutist and intolerant phrases that they add to their interests and make themselves unduly upset, should be put aside (32).

Since adjustment involves both the process of coping with the present conditions and also the process of changing environmental conditions to adapt to individual needs, it decreases environmental tensions for the person, that in turn lead to particularly suitable academic performance and, in the meantime, rational emotional behavior approach assists the individual in achieving this compliance in an appropriate manner.

In conclusion, regarding the findings of this study and considering the experience of researchers as teachers dealing with students' adjustment problems (different problems such as contradictions among the students, difficulty in coping with teachers, emotional adjustment problems and so on), the advantages of using rationalemotional-behavioral group therapy on resolving adjustment issues among students are as follows: first, this therapy addresses three rational, emotional and behavioral dimensions. Second, instead of emphasizing on the past, which is not reversible and usually is employed for justi- fication of present problems of students, this therapy provides the ground for patients to accept the responsibility of annoying themselves. Third, both the consultant and the patient are involved actively in learning during the term of therapy. Fourth, this method stresses on a series of factors, which have an effective role in treatment such as unconditional self-acceptance, flexible thinking, tolerance of failure, choice, and strong will. Fifth, during the treatment the patient finds a deep philosophical change and a whole new perspective on life.

\section{Acknowledgments}

The authors appreciate and thank all those who helped with this research and contributed to this investigation in any way, including students and school officials of Shahid Rajaee high school of Bostanabad Kamal city.

\section{References}

1. Shoarinejad AA. Growth Psychology. Tehran: PNU; 2009.

2. Papworth M. Getting on clinical psychology training courses: Responses to frequently asked questions. Clinical psychology-leicester. 2004:32-6.

3. Maleki TA. A comparative study of self-concept and social adjustment among blind and normal male students in Tehran. Tehran: Shahid Beheshti University; 2011.

4. Lotfi H. Social psychology: The psychology of conformity (theory and applications. Tehran: Didavar; 2002.

5. Pajares F. Gender and perceived self-efficacy in self-regulated learning. Theory into practice. 2002;41(2):116-25.

6. Sinha AKP, Singh RP. The adjustment Inventory for school students (AISS). National psychological corporation. 1993.

7. Matin A, Looyeh MY, Afrooz GA, Dezhkam M. The effect of group rational emotive behavior restructuring on mental health of parents of exceptional children. Procedia-Soci Behav Sci. 2012;46:1872-5.

8. Jahnson HD. Conflict goals associated with adolescent perceptions of relationship expection violation during conflicts with some-sex friends. In: Lee AV, editor. Psychology of coping. Newyork: Nova Publishing; 2005. pp. 43-65.

9. Muris P. Relationships between self-efficacy and symptoms of anxiety disorders and depression in a normal adolescent sample. Personality and individual differences. 2002;32(2):337-48.

10. Arip MA, Yusooff FB, Jusoh AJ, Salim S, Samad A. The effectiveness of cognitive behavioral therapy(CBT) treatment group on self-concept among adolescents. Inter J Human Soci Sci. 2011;1(18):113-22.

11. Corsini R. Current Psychotherapies.. Peacock Publishers; 2011. 
12. Dobson KS, Dozois DJA. Historical philosophical bases of the cognitive-behavioral therapies. In: K. S. Dobson, editor. Handbook of cognitive-behavioral therapies. 3 ed. New York: Guilford Press; 2010. pp. 3-38.

13. Kary J. Theory and application of counseling and psychotherapy. Tehran: Arasbaran; 2013.

14. Corsini R. Current psychotherapies. Taylor \& Francis; 2005.

15. Fava A, Giovani M. Cognetive behavior therapy Encyclopdia of stress. $2000 ; 9: 484-7$.

16. Zebardast YM, Golizade BL, Issa P. Group council effect regarding to its cognitive-behavioral-emotional factors in decreasing giral high school students anxiety. Soci Behav Sci. 2013;84:59-62.

17. Kim MA, Kim J, Kim EJ. Effects of rational emotive behavior therapy for senior nursing students on coping strategies and self-efficacy. Nurse education today. 2015;35(3):456-60.

18. Roghanchi M, Mohamad AR, Mey SC, Momeni KM, Golmohamadian $M$. The effect of integrating rational emotive behavior therapy and art therapy on self-esteem and resilience. Art Psychothe. 2013;40(2):17984.

19. Slobodskaya HR, Akhmetova OA. Personality development and problem behavior in Russian children and adolescents. Inter J Behav Develop. 2010.

20. Abdullah MC, Elias H, Mahyuddin R, Uli J. Adjustment amongst first students in a Malaysian university. Euro J Soci Sci. 2009;8(3):496-505.

21. Delavar A. Principles of theoretical and practical research in the humanities and social sciences. 3 ed. Tehran: Roshd; 2013.

22. Karami A. Translation of students' adjustment inventory. Tehran: Sina Research Institute of Behavioural Sciences; 2003.

23. Fouladchang $M$. The role of family patterns in adolescents adjustment. J Family Res. 2006;2(7):209-21.

24. Pashazadeh A. The relationship between the hidden curriculum with social adjustment among high school students of Maku city. Kharazmi University; 2013.

25. Mahmoudi KB, Bagherian F, Heidari M. Examining the role of self-regulation in the social adjustment of students. Developmental Psychology-Iranian Psychologists. 2014;10(40):90-9.

26. Sadat AM, Nadri K. The relationship between creativity and social adjustment and academic performance of high school students. J Res Educa Manage. 2011;3(2):17-27.

27. Baurain C, Nader-Grosbois N, Dionne C. Socio-emotional regulation in children with intellectual disability and typically developing children, and teachers' perceptions of their social adjustment. Res Dev Disabil. 2013;34(9):2774-87. doi: 10.1016/j.ridd.2013.03.022. [PubMed: 23810924].

28. Senra H, Barbosa F, Ferreira P, Vieira CR, Perrin PB, Rogers H, et al. Psychologic adjustment to irreversible vision loss in adults: a systematic review. Ophthalmology. 2015;122(4):851-61. doi: 10.1016/j.ophtha.2014.10.022. [PubMed: 25573719].

29. Ageiee J, Manzari TV, Hosseini R, Hashemizadeh V. Evaluating the effectiveness of cognitive behavior group therapy, group therapy meaning and integrating them to increase social adjustment of maladaptive students. Studty Health Psychol. 2012;6(3):6-13.

30. Paiab F. The effectiveness of Rational Emotive Behavior group therapy on reducing domestic violence in married male students of Islamic Azad University of Gachsaran. Marvdasht: Islamic Azad University of Marvdasht; 2012.

31. Dastbaz A, Yunesi J, Moradi A, Abraham D. Effectiveness of solutionbased group counseling on adjustment and self-efficacy of 1st grade high school male students in Shariar. Knowledge Res Applied Psychol. 2014;1(55):90-8.

32. Ellis A. How to stubbornly refuse to make yourself miserable about anything-yes, anything!. USA: Secaucus, NJ: Lyle \& Stuart.; 1988. 